
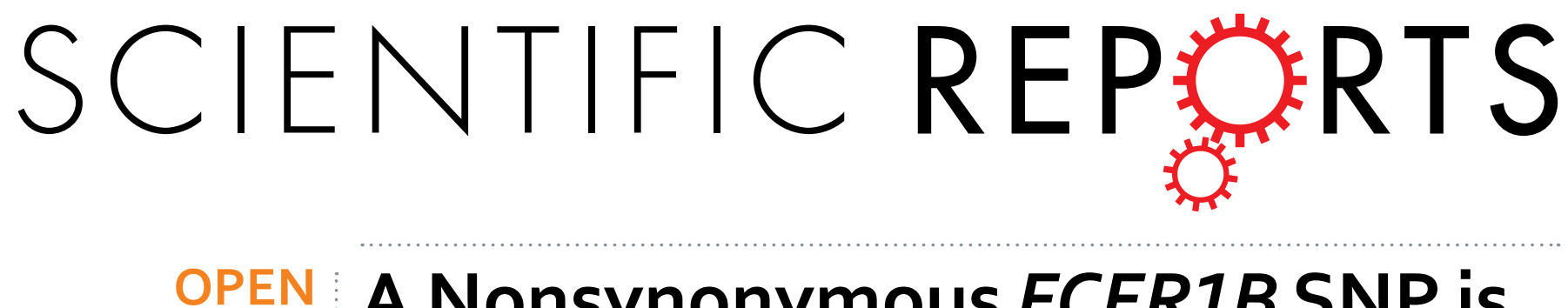

\title{
A Nonsynonymous FCER1B SNP is Associated with Risk of Developing Allergic Rhinitis and with IgE Levels
}

Received: 02 October 2015

Accepted: 09 December 2015

Published: 21 January 2016

\author{
Gemma Amo ${ }^{1}$, Jesús García-Menaya ${ }^{2}$, Paloma Campo ${ }^{3}$, Concepción Cordobés ${ }^{2}$, \\ M Carmen Plaza Serón ${ }^{1,3}$, Pedro Ayuso ${ }^{4}$, Gara Esguevillas ${ }^{1}$, Miguel Blanca ${ }^{3}$, \\ Jose A.G. Agúndez ${ }^{1}$ \& Elena García-Martín ${ }^{1}$
}

Allergic rhinitis is associated with elevated serum IgE levels. IgE response is mediated by the highaffinity IgE receptor (FcERI), which is polymorphic. Studies analyzing the association between allergic rhinitis and $F \subset \varepsilon R I$ variants have been conducted with controversial results. The objective of this study is to analyze, in 1,041 individuals, the putative clinical association of allergic rhinitis with common polymorphisms in FcERI subunits genes. These SNPs included FECR1A rs2494262, rs2427837 and rs2251746; FECR1B rs1441586, rs569108 and rs512555; FCER1G rs11587213, rs2070901 and rs11421. Statistically significant differences were observed for the FCER1B rs 569108 and rs512555 polymorphisms frequencies when comparing patients with allergic rhinitis without asthma and controls. The $\mathrm{OR}(95 \% \mathrm{Cl})$ value for the $237 \mathrm{Gly}$ allele $(\mathrm{rs} 569108)$ is equal to $0.26(0.08-0.86, \mathrm{P}=0.017)$ and for the $G$ allele ( $r 5512555)$ it is equal to $0.27(0.08-0.88, P=0.020)$. These two SNPs are linked $\left(D^{\prime}=1.0, L O D=56.05\right)$. Also observed was a statistically significant trend towards lower IgE values among allergic rhinitis patients with variant alleles for both SNPs. In conclusion, in patients with allergic rhinitis without asthma, the $F C E R 1 B$ rs 569108 and rs 512555 polymorphisms are associated with increased risk of developing allergic rhinitis and with lower IgE levels.

Allergic rhinitis is associated to family history of allergy ${ }^{1,2}$, thus suggesting that genetic risk factors may underlie the risk of developing, or the clinical presentation of, allergic rhinitis ${ }^{3-5}$. Allergic rhinitis is also associated to elevated serum IgE levels and increased mediator release from activated inflammatory cells. IgE cross-link allergens and bind the high-affinity IgE receptor $(\mathrm{F} c \varepsilon \mathrm{RI})$ on the surface of mast cells or basophils, releasing vasoactive mediators, such as histamine. Fc $\varepsilon$ RI on these cells is a heterotetramer of three subunits: Fc $\varepsilon$ RI $\alpha$, Fc $\varepsilon$ RI $\beta$ y Fc $\varepsilon$ RI $\gamma\left(\alpha \beta \gamma_{2}\right)$ encoded by three genes designated as FCER1A, FCER1B and FCER1G, respectively ${ }^{6,7}$. Fce RI $\alpha$ is the ligand-binding subunit, $F c \varepsilon R I \beta$ is a signal-augmenting subunit and $F c \varepsilon R I \gamma$ is a signal-transducing subunit $^{8}$. In other cells, such as antigen-presenting cells including monocytes, dendritic cells or macrophages, $\mathrm{Fc} \varepsilon \mathrm{RI}$ is expressed in a trimeric form lacking the $\beta$-subunit ${ }^{9,10}$. It also has been reported that platelets, epidermal Langerhans cells or eosinophils can express the receptor on their cellular surface in a trimeric form ${ }^{11,12}$.

Although the search for genetic susceptibility factors related to allergic rhinitis is a promising field, gene variations related to $\mathrm{F} c \varepsilon \mathrm{RI}$ as potential risk factors for allergic rhinitis have not been comprehensively analyzed, and the results available are in some cases contradictory ${ }^{5,13-17}$. The genes coding for all Fce RI subunits are polymorphic. Some of these polymorphisms affect IgE levels and/or have been associated with atopic diseases ${ }^{18-23}$. The FCER1A gene is located on chromosome 1q23 (1:159259504-159278014) ${ }^{24}$ and it encodes a protein with two extracellular IgE-like domains ${ }^{7}$. The FCER1B gene is located on chromosome 11q12-13. The gene spans approximately 10 kilobases (11:59855734-59863444) ${ }^{24}$, and it encodes a 244-amino acid protein with a non-canonic intracellular ITAM domain with an extra tyrosine. Fc $\varepsilon$ RI can be expressed without the $\beta$-chain, but when Fc $\varepsilon$ RI $\beta$ is present, receptor expression is higher ${ }^{7}$. The FCER1G gene is located on chromosome 1q23 (1:161185024$161190489)^{24}$. The gene encodes an 86-amino acid protein. FC $\varepsilon \mathrm{R} 1 \gamma$ plays an essential role in the induction of mast cell degranulation and survival ${ }^{25}$.

${ }^{1}$ Department of Pharmacology, Universidad de Extremadura, Cáceres, Spain. ${ }^{2}$ Allergy Service, University Hospital Infanta Cristina, Badajoz, Spain. ${ }^{3}$ Allergy Service, Hospital Carlos Haya, Málaga, Spain. ${ }^{4}$ Research Laboratory, IBIMAMálaga University General Hospital, Málaga, Spain. Correspondence and requests for materials should be addressed to E.G.-M. (email: elenag@unex.es) 


\begin{tabular}{|c|c|c|c|c|c|c|}
\hline & Group & \begin{tabular}{|c|}
$\begin{array}{c}\text { Non-mutated } \\
\text { (frequency) }\end{array}$ \\
\end{tabular} & \begin{tabular}{|c|}
$\begin{array}{c}\text { Heterozygous } \\
\text { (frequency) }\end{array}$ \\
\end{tabular} & $\begin{array}{l}\text { Homozygous } \\
\text { (frequency) }\end{array}$ & $\begin{array}{c}\text { Minor allele } \\
\text { frequency }\end{array}$ & $\begin{array}{l}\text { Comparison Allele frequency } \\
\text { OR ( } 95 \% \text { C.I.); P; Pc }\end{array}$ \\
\hline \multicolumn{7}{|l|}{ FCER1A } \\
\hline \multirow[t]{2}{*}{ rs 2494262} & Patients & 0.266 & 0.476 & 0.258 & 0.496 & $0.93(0.78-1.12) ; 0.411 ; 0.955$ \\
\hline & Controls & 0.237 & 0.498 & 0.265 & 0.514 & \\
\hline \multirow[t]{2}{*}{ rs2427837 } & Patients & 0.563 & 0.371 & 0.066 & 0.251 & $0.95(0.78-1.16) ; 0.814 ; 0.955$ \\
\hline & Controls & 0.539 & 0.399 & 0.062 & 0.262 & \\
\hline \multirow[t]{2}{*}{ rs2251746 } & Patients & 0.553 & 0.379 & 0.068 & 0.257 & $1.00(0.82-1.22) ; 0.872 ; 0.955$ \\
\hline & Controls & 0.545 & 0.395 & 0.060 & 0.258 & \\
\hline \multicolumn{7}{|l|}{ FCER1B } \\
\hline \multirow[t]{2}{*}{ rs1441586 } & Patients & 0.279 & 0.501 & 0.220 & 0.471 & $1.03(0.87-1.23) ; 0.500 ; 0.955$ \\
\hline & Controls & 0.274 & 0.526 & 0.200 & 0.463 & \\
\hline \multirow[t]{2}{*}{ rs569108 } & Patients & 0.926 & 0.074 & 0.000 & 0.037 & 0.99 (0.62-1.57); 0.955; 0.955 \\
\hline & \begin{tabular}{|l|} 
Controls \\
\end{tabular} & 0.925 & 0.075 & 0.000 & 0.037 & \\
\hline \multirow[t]{2}{*}{ rs512555 } & Patients & 0.928 & 0.072 & 0.000 & 0.036 & $0.99(0.62-1.57) ; 0.936 ; 0.955$ \\
\hline & Controls & 0.927 & 0.073 & 0.000 & 0.036 & \\
\hline \multicolumn{7}{|l|}{ FCER1G } \\
\hline \multirow[t]{2}{*}{ rs11587213 } & Patients & 0.718 & 0.262 & 0.019 & 0.150 & $0.96(0.75-1.22) ; 0.898 ; 0.955$ \\
\hline & Controls & 0.715 & 0.257 & 0.027 & 0.156 & \\
\hline \multirow[t]{2}{*}{ rs2070901 } & Patients & 0.526 & 0.384 & 0.089 & 0.282 & $0.94(0.78-1.14) ; 0.732 ; 0.955$ \\
\hline & Controls & 0.512 & 0.388 & 0.100 & 0.294 & \\
\hline \multirow[t]{2}{*}{ rs11421 } & Patients & 0.683 & 0.286 & 0.031 & 0.174 & $0.94(0.75-1.17) ; 0.773 ; 0.955$ \\
\hline & Controls & 0.679 & 0.274 & 0.047 & 0.184 & \\
\hline
\end{tabular}

Table 1. FCER1 genotypes in overall allergic rhinitis patients and control individuals. $P$ values correspond to stratified Chi-Square Tests. Pc correspond values adjusted for multiple comparisons according the False Discovery Rate (FDR) procedure. OR: odds ratio. CI: 95\% confidence interval.

Aiming to elucidate the putative association of common gene variants affecting the FceRI subunits in the clinical presentation and/or in risk of developing allergic rhinitis, we analyzed the association of the variants of FCER1A, FCER1B, FCER1G genes with several clinical phenotype parameters, including IgE levels, in a large group of well-phenotyped allergic rhinitis patients and control individuals; we also analyzed putative gene-gene interactions which, as yet, have not been explored.

\section{Results}

The SNP frequencies observed in the study group are consistent with those previously described in the 1000 genomes public database for individuals with European descent ${ }^{24}$, and are at Hardy-Weinberg equilibrium. The genotype and allele frequencies for the nine SNPs analyzed in overall allergic rhinitis patients and control individuals are summarized in Table 1. No major frequency differences were observed when comparing patients and controls.

Patients were stratified in two subgroups according to their clinical presentation; allergic rhinitis alone and allergic rhinitis + asthma. Table 2 shows the FCER1 genotypes. Among patients with allergic rhinitis alone the frequencies for individuals carrying the minor alleles for the SNPs rs569108 and rs512555 were remarkably reduced among allergic rhinitis patients as compared to the control individuals. In fact, only three allergic rhinitis patients (representing $2 \%$ of this clinical subgroup) carried such minor alleles in heterozygosity, whereas 37 controls $(7.2 \%)$ carried such variant alleles. It is to be noted that no carriers of these variant alleles in homozygosity were observed among all patients and controls (Table 1). Statistical significance was also observed in the test for trend for the SNPs rs569108 and $\operatorname{rs} 512555\left(\chi^{2}=5.86, P=0.015 ; \chi^{2}=5.60, P=0.018\right.$, respectively). The SNP rs569108 corresponds to a missense variant E237G, which is predicted as deleterious by Sorting Intolerant From Tolerant $(\mathrm{SIFT})^{26}$, and predicted as possibly damaging by the Polymorphism Phenotyping v2 (PolyPhen-2) prediction ${ }^{27}$. The SNP rs512555 is a downstream gene variant whose functional effect is unknown; the high linkage between these two SNPs in the present study $\left(D^{\prime}=1.0, \mathrm{LOD}=56.05\right)$ suggest that the genetic association observed in Table 2 might actually be related to the missense SNP rs569108. The rest of the SNPs analyzed did not reveal any differences either in genotypes or in allele frequencies, when patients with allergic rhinitis alone and control individuals were compared (Table 2). Among patients with allergic rhinitis + asthma none of the SNPs analyzed revealed significant differences when compared to control individuals (Table 2).

Because it has been suggested that FCER1 genotypes may modify IgE response ${ }^{21}$, we determined $\operatorname{IgE}$ values and analyzed their distribution according FCER1 genotypes. These findings are summarized in Table 3. A statistically significant trend can be observed towards lower IgE values among patients with variant alleles for the SNPs rs569108 and rs512555, confined to patients with allergic rhinitis alone. Among patients with allergic rhinitis + asthma who carried the above-mentioned variant alleles, the IgE values were lower as compared to non-carriers, but the difference was not statistically significant. The rest of the variant alleles were not related to the IgE levels. 


\begin{tabular}{|c|c|c|c|c|c|}
\hline Allergic rhinitis alone & $\begin{array}{c}\text { Non-mutated } \\
\text { (frequency) }\end{array}$ & $\begin{array}{c}\text { Heterozygous } \\
\text { (frequency) }\end{array}$ & $\begin{array}{l}\text { Homozygous } \\
\text { (frequency) }\end{array}$ & $\begin{array}{l}\text { Minor allele } \\
\text { frequency }\end{array}$ & $\begin{array}{l}\text { Comparison with controls Allele } \\
\text { frequency OR ( } 95 \% \text { C.I.); P; Pc }\end{array}$ \\
\hline \multicolumn{6}{|l|}{ FCER1A } \\
\hline rs2494262 & 0.275 & 0.503 & 0.221 & 0.473 & $0.85(0.66-1.10) ; 0.529 ; 0.842$ \\
\hline rs2427837 & 0.564 & 0.403 & 0.034 & 0.235 & 0.87 (0.64-1.17); $0.585 ; 0.842$ \\
\hline rs2251746 & 0.550 & 0.403 & 0.047 & 0.248 & $0.95(0.71-1.28) ; 0.655 ; 0.842$ \\
\hline \multicolumn{6}{|l|}{ FCER1B } \\
\hline rs1441586 & 0.315 & 0.450 & 0.235 & 0.460 & $0.99(0.76-1.28) ; 0.209 ; 0.627$ \\
\hline rs569108 & 0.980 & 0.020 & 0.000 & 0.010 & $0.26(0.08-0.86) ; 0.009 ; 0.041$ \\
\hline rs512555 & 0.980 & 0.020 & 0.000 & 0.010 & $0.27(0.08-0.88) ; 0.009 ; 0.041$ \\
\hline \multicolumn{6}{|l|}{ FCER1G } \\
\hline rs11587213 & 0.725 & 0.262 & 0.013 & 0.144 & $0.91(0.63-1.31) ; 0.891 ; 0.891$ \\
\hline rs2070901 & 0.523 & 0.409 & 0.067 & 0.272 & $0.90(0.67-1.20) ; 0.614 ; 0.842$ \\
\hline rs11421 & 0.709 & 0.257 & 0.034 & 0.162 & $0.86(0.61-1.22) ; 0.845 ; 0.891$ \\
\hline Allergic rhinitis + Asthma & $\begin{array}{l}\text { Non-mutated } \\
\text { (frequency) }\end{array}$ & $\begin{array}{c}\text { Heterozygous } \\
\text { (frequency) }\end{array}$ & $\begin{array}{c}\text { Homozygous } \\
\text { (frequency) }\end{array}$ & $\begin{array}{l}\text { Minor allele } \\
\text { frequency }\end{array}$ & $\begin{array}{l}\text { Comparison with controls Allele } \\
\text { frequency OR (95\% C.I.); P; Pc }\end{array}$ \\
\hline \multicolumn{6}{|l|}{ FCER1A } \\
\hline rs2494262 & 0.266 & 0.467 & 0.266 & 0.500 & $0.95(0.78-1.15) ; 0.416 ; 0.769$ \\
\hline rs2427837 & 0.569 & 0.350 & 0.081 & 0.256 & $0.97(0.78-1.22) ; 0.511 ; 0.769$ \\
\hline rs2251746 & 0.560 & 0.359 & 0.081 & 0.260 & $1.02(0.81-1.27) ; 0.598 ; 0.769$ \\
\hline \multicolumn{6}{|l|}{ FCER1B } \\
\hline rs1441586 & 0.274 & 0.512 & 0.214 & 0.470 & $1.03(0.84-1.25) ; 0.579 ; 0.769$ \\
\hline rs569108 & 0.901 & 0.099 & 0.000 & 0.050 & 1.34 (0.83-2.17); $0.461 ; 0.769$ \\
\hline rs512555 & 0.904 & 0.096 & 0.000 & 0.048 & $1.33(0.82-2.16) ; 0.553 ; 0.769$ \\
\hline \multicolumn{6}{|l|}{ FCER1G } \\
\hline rs11587213 & 0.716 & 0.266 & 0.018 & 0.151 & $0.96(0.74-1.26) ; 0.881 ; 0.881$ \\
\hline rs2070901 & 0.527 & 0.374 & 0.099 & 0.286 & $0.96(0.77-1.19) ; 0.762 ; 0.857$ \\
\hline rs11421 & 0.671 & 0.302 & 0.027 & 0.178 & $0.96(0.75-1.24) ; 0.541 ; 0.769$ \\
\hline
\end{tabular}

Table 2. FCER1 genotypes in patients with allergic rhinitis classified according the presence of asthma.

Since a statistical significant association of the FCER $1 B$ variant alleles with IgE levels in patients with allergic rhinitis alone was detected, linear regression under the standard additive model, including in a single model all genotypes, gender, age, familial antecedents of allergic diseases, smoking and prick tests, was studied with regard to the IgE values. Only age, with lower IgE concentrations in older age, $(p=0.019)$ and the mutated genotypes corresponding to the FCER1B SNPs rs569108 and rs512555 genotypes $(\mathrm{p}=0.005)$ remained significant. The rest of the putative genetic associations were discarded in the multiple analysis. No associations of genotypes or $\operatorname{IgE}$ levels were identified when individuals were stratified with regard to allergic rhinitis type (intermittent, persistent mild and persistent moderate), eosinophilia, FEV or asthma severity step.

\section{Discussion}

Allergic rhinitis, like other complex diseases, results from interplay of genetic and environmental risk factors ${ }^{3-5}$. The heritability factor has been calculated to be quite high, between $74-82 \%^{1}$ and $90 \%{ }^{2}$, and several genetic variants are known to be associated with allergic rhinitis risk in some populations ${ }^{3,28,29}$. However, associations have been described with genes which have a weak, or unknown, relation with allergic rhinitis pathogenesis, and it has been speculated that the putative associations could be due to hitherto unknown epigenetic mechanisms ${ }^{3}$. In contrast, the present study focuses on genes that are functionally related to the pathogenesis and the clinical presentation of this disease.

Our results show association of two SNPs in the FCER1B gene with the risk of developing allergic rhinitis: the nonsynonymous Glu237Gly (rs569108) and the 3'UTR SNP (rs512555). The Glu237 allele is more common among allergic rhinitis alone patients than in healthy subjects. When allergic rhinitis + asthma patients were compared to healthy subjects, we observed no statistically significant differences in the allele frequencies or genotypes. The FCER1B Glu237Gly variant has been studied in a Japanese population (233 patients with nasal allergy and 100 control subjects) showing an association between Gly 237 and nasal allergy and atopy ${ }^{30}$. Recently, a meta-analysis including these two polymorphisms ${ }^{16}$ has been published. Such study includes 4496 asthmatics and 4571 controls for the E237G variant and 2005 cases and 1868 controls for rs 1441586 from several populations: Caucasians, Africans and Asians. The results obtained suggest that the $237 \mathrm{Gly}$ allele might influence the risk for developing atopic asthma, although no significant association was observed in the total population. Regarding the rs1441586 SNP, a significant association with asthma risk was observed among Asians only ${ }^{16}$. Our findings do not support such an association with asthma, but they do support association with rhinitis. To date, no meta-analyses with allergic rhinitis patients have been performed. The close relationship between asthma and allergic rhinitis is well known. A majority of adult patients with asthma also suffer from allergic rhinitis ${ }^{17}$ and vice-versa (this study). However, the presence or absence of allergic rhinitis + asthma can be an important confounding factor 


\begin{tabular}{|c|c|c|c|c|c|c|c|}
\hline & Genotype & $\begin{array}{l}\text { Allergic rhinitis } \\
\text { alone }\end{array}$ & $\begin{array}{c}\text { K-W Test } \\
\text { across } \\
\text { genotypes } \\
\text { P; Pc }\end{array}$ & $\begin{array}{c}\text { Allergic } \\
\text { rinitis + Asthma }\end{array}$ & $\begin{array}{l}\text { K-W Test } \\
\text { across } \\
\text { genotypes } \\
\text { P; Pc }\end{array}$ & Overall patients & $\begin{array}{c}\text { K-W Test } \\
\text { across } \\
\text { genotypes } \\
\text { P; Pc }\end{array}$ \\
\hline \multicolumn{8}{|l|}{ FCER1A } \\
\hline \multirow[t]{3}{*}{ rs2494262 } & $\mathrm{C} / \mathrm{C}$ & $184.94 \pm 232.47$ & \multirow{3}{*}{$\begin{array}{l}\mathrm{P}=0.139 \\
\mathrm{Pc}=0.250\end{array}$} & $346.51 \pm 482.83$ & \multirow{3}{*}{$\begin{array}{l}\mathrm{P}=0.560 \\
\mathrm{Pc}=0.937\end{array}$} & $294.33 \pm 424.13$ & \multirow{3}{*}{$\begin{array}{l}\mathrm{P}=0.935 \\
\mathrm{Pc}=0.972\end{array}$} \\
\hline & $\mathrm{C} / \mathrm{A}$ & $187.68 \pm 188.84$ & & $267.86 \pm 333.20$ & & $239.74 \pm 293.54$ & \\
\hline & $\mathrm{A} / \mathrm{A}$ & $266.87 \pm 292.81$ & & $306.76 \pm 634.82$ & & $297.62 \pm 555.56$ & \\
\hline \multirow[t]{3}{*}{ rs2427837 } & G/G & $194.33 \pm 226.68$ & \multirow{3}{*}{$\begin{array}{l}\mathrm{P}=0.343 \\
\mathrm{Pc}=0.514\end{array}$} & $300.01 \pm 412.43$ & \multirow{3}{*}{$\begin{array}{l}\mathrm{P}=0.937 \\
\mathrm{Pc}=0.937\end{array}$} & $265.68 \pm 362.08$ & \multirow{3}{*}{$\begin{array}{l}\mathrm{P}=0.841 \\
\mathrm{Pc}=0.972\end{array}$} \\
\hline & G/A & $226.68 \pm 241.53$ & & $290.18 \pm 558.77$ & & $267.13 \pm 468.99$ & \\
\hline & $\mathrm{A} / \mathrm{A}$ & $140.60 \pm 118.43$ & & $328.59 \pm 421.92$ & & $298.76 \pm 384.97$ & \\
\hline \multirow[t]{3}{*}{ rs2251746 } & $\mathrm{T} / \mathrm{T}$ & $190.06 \pm 226.53$ & \multirow{3}{*}{$\begin{array}{l}\mathrm{P}=0.034 \\
\mathrm{c}=0.102\end{array}$} & $298.66 \pm 413.61$ & \multirow{3}{*}{$\begin{array}{l}\mathrm{P}=0.915 \\
\mathrm{Pc}=0.937\end{array}$} & $263.74 \pm 368.07$ & \multirow{3}{*}{$\begin{array}{l}\mathrm{P}=0.372 \\
\mathrm{Pc}=0.837\end{array}$} \\
\hline & $\mathrm{T} / \mathrm{C}$ & $238.70 \pm 238.76$ & & $297.09 \pm 554.46$ & & $276.18 \pm 466.41$ & \\
\hline & $\mathrm{C} / \mathrm{C}$ & $105.86 \pm 113.70$ & & $302.71 \pm 425.47$ & & $255.75 \pm 376.03$ & \\
\hline \multicolumn{8}{|l|}{ FCER1B } \\
\hline \multirow[t]{3}{*}{ rs1441586 } & $\mathrm{T} / \mathrm{T}$ & $176.95 \pm 174.85$ & \multirow{3}{*}{$\begin{array}{l}\mathrm{P}=0.098 \\
\mathrm{Pc}=0.221\end{array}$} & $267.91 \pm 326.28$ & \multirow{3}{*}{$\begin{array}{l}\mathrm{P}=0.344 \\
\mathrm{Pc}=0.830\end{array}$} & $233.06 \pm 280.70$ & \multirow{3}{*}{$\begin{array}{l}\mathrm{P}=0.972 \\
\mathrm{Pc}=0.972\end{array}$} \\
\hline & $\mathrm{T} / \mathrm{C}$ & $236.85 \pm 248.41$ & & $286.22 \pm 399.42$ & & $272.75 \pm 361.14$ & \\
\hline & $\mathrm{C} / \mathrm{C}$ & $181.37 \pm 252.96$ & & $374.63 \pm 738.18$ & & $303.91 \pm 616.37$ & \\
\hline \multirow[t]{3}{*}{ rs569108 } & $\mathrm{A} / \mathrm{A}$ & $210.43 \pm 229.10$ & \multirow{3}{*}{$\begin{array}{l}\mathrm{P}=0.006 \\
\mathrm{Pc}=0.027\end{array}$} & $309.51 \pm 487.16$ & \multirow{3}{*}{$\begin{array}{l}\mathrm{P}=0.242 \\
\mathrm{Pc}=0.830\end{array}$} & $275.40 \pm 419.36$ & \multirow{3}{*}{$\begin{array}{l}\mathrm{P}=0.114 \\
\mathrm{Pc}=0.549\end{array}$} \\
\hline & $\mathrm{A} / \mathrm{G}$ & $11.00 \pm 4.58$ & & $175.38 \pm 165.47$ & & $160.91 \pm 164.89$ & \\
\hline & $\mathrm{G} / \mathrm{G}$ & - & & - & & - & \\
\hline \multirow[t]{3}{*}{ rs512555 } & $\mathrm{C} / \mathrm{C}$ & $210.43 \pm 229.10$ & \multirow{3}{*}{$\begin{array}{l}\mathrm{P}=0.006 \\
\mathrm{Pc}=0.027\end{array}$} & $308.11 \pm 485.44$ & \multirow{3}{*}{$\begin{array}{l}\mathrm{P}=0.369 \\
\mathrm{Pc}=0.830\end{array}$} & $274.67 \pm 418.34$ & \multirow{3}{*}{$\begin{array}{l}\mathrm{P}=0.183 \\
\mathrm{Pc}=0.549\end{array}$} \\
\hline & $\mathrm{C} / \mathrm{T}$ & $11.00 \pm 4.58$ & & $182.70 \pm 166.24$ & & $166.91 \pm 166.18$ & \\
\hline & $\mathrm{T} / \mathrm{T}$ & - & & - & & - & \\
\hline \multicolumn{8}{|l|}{ FCER1G } \\
\hline \multirow[t]{3}{*}{ rs11587213 } & $\mathrm{A} / \mathrm{A}$ & $200.60 \pm 231.02$ & \multirow{3}{*}{$\begin{array}{l}\mathrm{P}=0.954 \\
\mathrm{Pc}=0.954\end{array}$} & $310.60 \pm 510.95$ & \multirow{3}{*}{$\begin{array}{l}\mathrm{P}=0.737 \\
\mathrm{Pc}=0.937\end{array}$} & $273.55 \pm 440.24$ & \\
\hline & $\mathrm{A} / \mathrm{G}$ & $224.68 \pm 229.73$ & & $257.38 \pm 307.77$ & & $249.42 \pm 285.10$ & $\begin{array}{l}\mathrm{P}=0.921 ; \\
\mathrm{P}_{\mathrm{C}}=0.972\end{array}$ \\
\hline & G/G & $152.00 \pm 80.61$ & & $380.17 \pm 666.52$ & & $323.13 \pm 573.94$ & \\
\hline rs2070901 & $\mathrm{G} / \mathrm{G}$ & $211.39 \pm 219.17$ & & $299.32 \pm 421.34$ & & $271.91 \pm 370.55$ & \\
\hline & $\mathrm{G} / \mathrm{T}$ & $187.57 \pm 181.20$ & $\begin{array}{l}\mathrm{P}=0.843 \\
\mathrm{P}_{\mathrm{C}}=0.954\end{array}$ & $312.20 \pm 576.70$ & $\begin{array}{l}\mathrm{P}=0.834 \\
\mathrm{PC}_{\mathrm{C}}=0.937\end{array}$ & $267.26 \pm 476.60$ & $\begin{array}{l}\mathrm{P}=0.969 \\
\mathrm{P}_{\mathrm{c}}=0.972\end{array}$ \\
\hline & $\mathrm{T} / \mathrm{T}$ & $279.13 \pm 489.95$ & & $247.19 \pm 244.88$ & & $254.28 \pm 307.33$ & \\
\hline rs11421 & $\mathrm{T} / \mathrm{T}$ & $201.13 \pm 232.38$ & & $269.59 \pm 464.41$ & & $274.04 \pm 401.77$ & \\
\hline & $\mathrm{T} / \mathrm{C}$ & $225.03 \pm 232.90$ & $\begin{array}{l}\mathrm{P}=0.918 \\
\mathrm{P} C=0.954\end{array}$ & $338.47 \pm 464.41$ & $\begin{array}{l}P=0.089 \\
P_{c}=0.801\end{array}$ & $305.21 \pm 421.82$ & $\begin{array}{l}\mathrm{P}=0.163 ; \\
\mathrm{P}_{\mathrm{c}}=0.549\end{array}$ \\
\hline & $\mathrm{C} / \mathrm{C}$ & $143.67 \pm 52.71$ & & $587.43 \pm 471.60$ & & $430.36 \pm 426.20$ & \\
\hline
\end{tabular}

Table 3. IgE values according to FCER1 genotypes. P values correspond to Kruskal-Wallis tests for independent samples. Pc correspond values adjusted for multiple comparisons according the False Discovery Rate (FDR) procedure. K-W test: Kruskall-Wallis test.

in the studies carried out so far, which did not discriminate these clinical presentations. In this sense careful phenotyping using strictly defined guidelines should be used to elucidate whether the putative associations with FECR1 polymorphisms are related to asthma or to concomitant allergic rhinitis. In this sense, we cannot rule out that environmental factors may modify the observed associations. Further PheWas studies would be necessary to elucidate this point.

The functional mechanism underlying the association found in our study is a matter of speculation, and there are certain aspects which should be taken into consideration. The regulation of the expression of Fc $\varepsilon$ RI is crucial to the receptor function. It is known that both the expression of Fc $\varepsilon \mathrm{RI} \beta$ subunit and the serum levels of IgE are important regulating factors. Fc $\varepsilon$ RI $\beta$ regulates the receptor response to IgE through its capacity to amplifying receptor signaling. IgE- Fc $\varepsilon$ RI binding causes overexpression of the receptor ${ }^{18,20}$ with an increase in the total FceRI $\alpha$ content on the surface. This process can be reverted by the removal of IgE, which results in a reduction in receptor expression and $\mathrm{Fc} \varepsilon \mathrm{RI} \alpha$ content ${ }^{19}$. The relation between FCER1B variants and IgE levels is controversial. A wide variation in the IgE levels, consistent with previous studies, was observed in the present study ${ }^{31,32}$. We observed that the FCER1B variants are associated with lower serum IgE levels, in a group of patients phenotyped to discriminate between patients with allergic rhinitis without asthma and allergic rhinitis + asthma. The association is lost when all allergic rhinitis patients are merged as a single clinical group, as has been done in most previous studies. Another source of variability with previous findings is that the variant alleles analyzed in this study show different frequencies in diverse ethnicities ${ }^{24}$; these differences could explain, at least in part, the different results described to date.

Several studies have reported an association between several FCER1A variants and total serum $\operatorname{IgE}$ levels ${ }^{21}$ as well as increased risk for atopic eczema and asthma. We failed to replicate the previously described association of IgE levels with the FCER1A polymorphism rs2427837, although it is important to note that this association was described in a specific population corresponding to a general population of individuals living in Augsburg ${ }^{21}$. 


\begin{tabular}{|l|c|c|c|c|}
\hline & $\begin{array}{c}\text { Overall patients with allergic } \\
\text { rhinitis }(\mathbf{n}=\mathbf{5 1 5})\end{array}$ & $\begin{array}{c}\text { Patients with allergic rhinitis plus } \\
\text { asthma (n= 366) }\end{array}$ & $\begin{array}{c}\text { Patients with allergic } \\
\text { rhinitis alone (n= 149) }\end{array}$ & Healthy subjects (n= 526) \\
\hline Women, $\mathrm{n}(\%)$ & $294(57.1 \%)$ & $193(52.7 \%)$ & $82(55.0 \%)$ & $265(50.4 \%)$ \\
\hline Age \pm sd (range) & $32.2 \pm 15.1(14-79)$ & $30.1 \pm 13.2(14-79)$ & $32.5 \pm 16.5(14-77)$ & $28.4 \pm 12.1(18-84)$ \\
\hline Smokers, $\mathrm{n}(\%)$ & $151(29.3 \%)$ & $82(22.4 \%)$ & $69(46.3 \%)$ & $168(31.9 \%)$ \\
\hline Familial antecedents, $\mathrm{n}(\%)$ & $206(40.0 \%)$ & $155(42.3 \%)$ & $51(34.2 \%)$ & $0(0 \%)$ \\
\hline Total IgE (IU/mL) \pm sd (range) & $254.1 \pm 401.5(0-4800)$ & $287.2 \pm 464.1(0-4800)$ & $205.7 \pm 228.4(4-1469)$ & not determined \\
\hline Eosinophilia, $\mathrm{n}(\%)$ & $88(17.0 \%)$ & $86(23.4 \%)$ & $2(1.3 \%)$ & not determined \\
\hline Allergic rhinitis type, $\mathrm{n}(\%)$ & $116 / 239 / 160(22.5 / 46.4 / 74.4)$ & $62 / 185 / 119(16.9 / 50.5 / 32.5)$ & $54 / 54 / 41^{(2)}(34.2 / 34.2 / 27.5)$ & n.a. \\
\hline FEV ${ }_{1}(\%$ predicted) & n.a. & $94 \pm 62$ & n.a. & n.a. \\
\hline Asthma severity step $1,2,3,4, \mathrm{n}(\%)$ & n.a. & $106 / 130 / 107 / 23(29.0 / 35.5 / 29.2 / 6.3)$ & n.a. & n.a. \\
\hline
\end{tabular}

Table 4. Characteristics of the individuals included in the study. Eosinophilia is defined as an eosinophils count over $400 / \mathrm{ml}$ or over $6 \%$ of white cells. The category smokers includes ex-smokers. Allergic rhinitis type was classified as follows (intermittent, persistent mild and persistent moderate). n.a. Not applicable. FEV: Forced expiratory volume.

Another study in a Han Chinese population failed to find an association between FCER1A variants and IgE level or allergic allergic rhinitis susceptibility ${ }^{22}$.

Summing up, we have identified an association of FCER1B variants with the risk of developing allergic rhinitis alone, and with IgE levels in these patients. Further association studies using well-phenotyped patients are required to identify genetic associations that, so far, may have been overlooked in studies considering heterogeneous groups of patients.

\section{Methods}

Study Population. We studied a cohort of 1,041 individuals, composed of 515 unrelated patients with allergic rhinitis and 526 unrelated healthy controls. Written consent for participation was obtained for all participants. All the patients and $97 \%$ of the control subjects who were invited to participate in the study agreed to do so.

Of the patients, 265 were recruited from the Allergy Department, Infanta Cristina Hospital (Badajoz, Spain) and 250 were recruited from the UGC Allergy, Regional Hospital (Málaga, Spain). Clinical characteristics of the participants are summarized in Table 4. Most of these patients had participated in a previous study and their clinical characterization has been described elsewhere ${ }^{33}$. Diagnosis for allergic rhinitis was based on the diagnostic criteria defined by the Joint Task Force on Practice Parameters in Allergy, Asthma and Immunology ${ }^{34}$. All patients were diagnosed by an allergy specialist and had a positive skin prick test ${ }^{35}$ for one or more aeroallergens. Of the 515 patients with allergic rhinitis, 366 (71.1\%) was diagnosed with allergic asthma, according to American Thoracic Society criteria ${ }^{36}$. These patients were classified as defined by the step classification of the Global Initiative for Asthma guidelines ${ }^{37}$. A total of 526 unrelated healthy controls, from the same geographic area, and ethnically matched with patients, were included in the study. Medical history was obtained and examination was performed for each participant to exclude pre-existing disorders. Individuals with familial (up to second-degree relatives) or personal antecedents of allergic, atopic or autoimmune diseases were excluded. Control subjects were selected from staff and from medical students belonging to the Hospitals and the Universities participating in the study.

No statistically significant differences between cases and controls were observed for gender. Age was not different when comparing the overall group of patients and controls ( $\mathrm{T}$-Test $\mathrm{P}=0.190$ ). However patients with allergic rhinitis alone had a mean age slightly lower than controls $(\mathrm{P}=0.035)$. The percentage of smokers was lower among patients with rhinitis plus asthma (Chi-Square test $\mathrm{P}=0.002$ ) as compared to control individuals, whereas the percentage of smokers was higher among patients with allergic rhinitis alone $(\mathrm{P}=0.002)$ as compared to control individuals. The protocol for this study was in accordance with the Declaration of Helsinki and its subsequent revisions, and it was approved by the respective Ethics Committees of the participating Hospitals. All individuals were Spanish Caucasians.

Genotype analysis. Genomic DNA was obtained from leukocytes and purified according to standard procedures. The selection of the SNPs analyzed was based on allele frequencies in the study population (higher than 0.01 ), as well as functional or clinical relevance, in accordance with the public 1000 genomes database $\mathrm{e}^{24}$ and published evidence ${ }^{38,39}$. SNP analyses were performed by means of TaqMan assays (Life Technologies, Alcobendas, Spain). Details of these assays are provided in supplemental Table S1. Detection was carried out by qPCR in a 7500 Real Time qPCR system (Life Technologies, Alcobendas, Spain). The amplification conditions were those recommended for the manufacturer. All SNP analyses were carried out in triplicate.

Statistical analyses. Statistical analyses were carried out by using the Statistical Package for the Social Sciences (SPSS) version 19.0 for Windows (SPSS Inc., Chicago, Ill. USA). Genotype, allelic and Hardy-Weinberg equilibrium analyses were performed by using the software PLINK ${ }^{40}$.

The comparison of the frequencies for alleles and genotypes between patients and control individuals was performed with the $\chi^{2}$ statistics or Fisher exact test, as appropriate. The putative association between the SNPs and the risk of developing rhinitis was estimated by determining the odds ratio (OR) and the $95 \%$ confidence interval (CI). Multiple comparison adjustments were done by using the False Discover Rate (FDR) $\operatorname{correction}^{41}$. 
The statistical significance of the differences in analytical or clinical parameters were calculated by using the non-parametric Kruskall-Wallis test for independent samples. The gene-dose effect was analyzed by using the test for trend (Cochran-Armitage test). Potential confounders considered in this study were the type of allergic rhinitis, age, gender, familial antecedents of the disease, smoking habits, the presence of asthma and asthma severity step. Multiple analyses were performed by using logistic regression. Differences in the parameters determined were considered to be statistically significant when adjusted $\mathrm{p}$ values were lower than 0.05 .

In order to calculate the statistical power of the study, we evaluated the sample size with a genetic model based on the frequency for carriers of the risk SNP with an OR value $=2(\alpha=0.05)$. According to the sample size in this study, the statistical power (two-sided associations) for the risk related to the presence of the variant alleles was higher than $99.8 \%$ for all SNPs except for the SNPs rs569108 (power $=93.2 \%$ ) and rs512555 (power $=92.6 \%$ ).

\section{References}

1. Rasanen, M., Laitinen, T., Kaprio, J., Koskenvuo, M. \& Laitinen, L. A. Hay fever-a Finnish nationwide study of adolescent twins and their parents. Allergy 53, 885-90 (1998).

2. van Beijsterveldt, C. E. \& Boomsma, D. I. Genetics of parentally reported asthma, eczema and rhinitis in 5-yr-old twins. Eur Respir J 29, 516-21 (2007)

3. Andiappan, A. K. et al. Replication of genome-wide association study loci for allergic rhinitis and house dust mite sensitization in an Asian population of ethnic Chinese in Singapore. J Allergy Clin Immunol 131, 1431-3 e8 (2013).

4. Nilsson, D. et al. Poor reproducibility of allergic rhinitis SNP associations. PLoS One 8, e53975 (2013).

5. Andiappan, A. K. et al. Investigating highly replicated asthma genes as candidate genes for allergic rhinitis. BMC Med Genet 14, 51 (2013).

6. Kinet, J. P. The high-affinity IgE receptor (Fc epsilon RI): from physiology to pathology. Annu Rev Immunol 17, 931-72 (1999).

7. Potaczek, D. P. \& Kabesch, M. Current concepts of IgE regulation and impact of genetic determinants. Clin Exp Allergy 42, 852-71 (2012).

8. Kraft, S. \& Kinet, J. P. New developments in FcepsilonRI regulation, function and inhibition. Nat Rev Immunol 7, 365-78 (2007).

9. Maurer, D. et al. Expression of functional high affinity immunoglobulin E receptors (Fc epsilon RI) on monocytes of atopic individuals. J Exp Med 179, 745-50 (1994).

10. Foster, B., Metcalfe, D. D. \& Prussin, C. Human dendritic cell 1 and dendritic cell 2 subsets express FcepsilonRI: correlation with serum IgE and allergic asthma. J Allergy Clin Immunol 112, 1132-8 (2003).

11. Bieber, T. et al. New insights in the structure and biology of the high affinity receptor for IgE (Fc epsilon RI) on human epidermal Langerhans cells. J Dermatol Sci 13, 71-5 (1996).

12. Dehlink, E. et al. A soluble form of the high affinity IgE receptor, Fc-epsilon-RI, circulates in human serum. PLoS One 6, e19098 (2011).

13. Shirakawa, T. et al. Association between atopic asthma and a coding variant of Fc epsilon RI beta in a Japanese population. Hum Mol Genet 5, 2068 (1996).

14. Shirakawa, T. et al. Association between Fc epsilon RI beta and atopic disorder in a Japanese population. Lancet 347, 394-5 (1996).

15. Green, S. L., Gaillard, M. C., Song, E., Dewar, J. B. \& Halkas, A. Polymorphisms of the beta chain of the high-affinity immunoglobulin E receptor (Fcepsilon RI-beta) in South African black and white asthmatic and nonasthmatic individuals. Am J Respir Crit Care Med 158, 1487-92 (1998).

16. Yang, H. J., Zheng, L., Zhang, X. F., Yang, M. \& Huang, X. Association of the MS4A2 gene promoter C-109T or the 7th exon E237G polymorphisms with asthma risk: a meta-analysis. Clin Biochem 47, 605-11 (2014).

17. Bousquet, J. et al. Allergic Rhinitis and its Impact on Asthma (ARIA) 2008 update (in collaboration with the World Health Organization, GA(2)LEN and AllerGen). Allergy 63 Suppl 86, 8-160 (2008).

18. Saini, S. S. et al. Down-regulation of human basophil IgE and FC epsilon RI alpha surface densities and mediator release by anti-IgEinfusions is reversible in vitro and in vivo. J Immunol 162, 5624-30 (1999).

19. MacGlashan, D. Jr. et al. In vitro regulation of FcepsilonRIalpha expression on human basophils by IgE antibody. Blood $91,1633-43$ (1998).

20. MacGlashan, D. Jr. et al. Upregulation of FcepsilonRI on human basophils by IgE antibody is mediated by interaction of IgE with FcepsilonRI. J Allergy Clin Immunol 104, 492-8 (1999).

21. Weidinger, S. et al. Genome-wide scan on total serum IgE levels identifies FCER1A as novel susceptibility locus. PLoS Genet 4, e1000166 (2008).

22. Zhang, Y. et al. SNPs in the FCER1A gene region show no association with allergic rhinitis in a Han Chinese population. PLoS One 5, e15792 (2010).

23. Li, X., Gibson, A. W. \& Kimberly, R. P. Human FcR polymorphism and disease. Curr Top Microbiol Immunol 382, 275-302 (2014).

24. 1000_Genomes. A Deep Catalog of Human Genetic Variation, 2015. Available from: http://browser.1000genomes.org/index.html [Last accessed 15 September 2015].

25. Manikandan, J., Kothandaraman, N., Hande, M. P. \& Pushparaj, P. N. Deciphering the structure and function of FcepsilonRI/mast cell axis in the regulation of allergy and anaphylaxis: a functional genomics paradigm. Cell Mol Life Sci 69, 1917-29 (2012).

26. Kumar, P., Henikoff, S. \& Ng, P. C. Predicting the effects of coding non-synonymous variants on protein function using the SIFT algorithm. Nat Protoc 4, 1073-81 (2009).

27. Adzhubei, I. A. et al. A method and server for predicting damaging missense mutations. Nat Methods 7, 248-9 (2010).

28. Ramasamy, A. et al. A genome-wide meta-analysis of genetic variants associated with allergic rhinitis and grass sensitization and their interaction with birth order. J Allergy Clin Immunol 128, 996-1005 (2011).

29. Bonnelykke, K. et al. Meta-analysis of genome-wide association studies identifies ten loci influencing allergic sensitization. Nat Genet 45, 902-6 (2013).

30. Nagata, H. et al. Association between nasal allergy and a coding variant of the Fc epsilon RI beta gene Glu237Gly in a Japanese population. Hum Genet 109, 262-6 (2001).

31. Garcia-Martin, E. et al. Polymorphisms of histamine-metabolizing enzymes and clinical manifestations of asthma and allergic rhinitis. Clin Exp Allergy 37, 1175-82 (2007).

32. Garcia-Martin, E. et al. Genetic determinants of metamizole metabolism modify the risk of developing anaphylaxis. Pharmacogenet Genomics 25, 462-4 (2015).

33. Gervasini, G. et al. Variability of the L-Histidine decarboxylase gene in allergic rhinitis. Allergy 65, 1576-84 (2010).

34. Dykewicz, M. S. et al. Diagnosis and management of rhinitis: complete guidelines of the Joint Task Force on Practice Parameters in Allergy, Asthma and Immunology. American Academy of Allergy, Asthma, and Immunology. Ann Allergy Asthma Immunol 81, 478-518 (1998).

35. Dreborg, S. Skin testing. The safety of skin tests and the information obtained from using different methods and concentrations of allergen. Allergy 48, 473-5 (1993). 
36. American_Thoracic_Society. Standards for the diagnosis and care of patients with chronic obstructive pulmonary disease (COPD) and asthma. This official statement of the American Thoracic Society was adopted by the ATS Board of Directors, November 1986. Am Rev Respir Dis 136, 225-44 (1987).

37. Global_Initiative_for_Asthma. Global Strategy for Asthma management and prevention: NHLBI/WHO workshop report, updated 2004: Bethesda (MD): National Institutes of Health, National Heart, Lung and Blood Institute. Publication no. 02-3659 (2004).

38. Kuster, H., von Manstein, S., Ruocchio-Wiglinghaus, S., von Brunn, A. \& Reinhardt, D. Mutations in the high-affinity IgE receptor beta-chain are not associated with nonresponder status. Allergy 60, 1040-5 (2005).

39. Rigoli, L. et al. Molecular analysis of sequence variants in the Fcepsilon receptor I beta gene and IL-4 gene promoter in Italian atopic families. Allergy 59, 213-8 (2004).

40. Purcell, S. et al. PLINK: a tool set for whole-genome association and population-based linkage analyses. Am J Hum Genet 81, 559-75 (2007).

41. Benjamini, Y., Drai, D., Elmer, G., Kafkafi, N. \& Golani, I. Controlling the false discovery rate in behavior genetics research. Behav Brain Res 125, 279-84 (2001).

\section{Acknowledgements}

This study was financed by grants PI12/00241, PI12/00324 and RETICS RD12/0013/0002 from Fondo de Investigación Sanitaria, Instituto de Salud Carlos III, Spain, and GR15026 from Junta de Extremadura, Spain. Financed in part with FEDER funds from the European Union. The authors are grateful to Professor James McCue for assistance in language editing.

\section{Author Contributions}

Conceived and designed the experiments: E.G.M. Performed the experiments: G.A. Analyzed the data: J.A.G.A. and E.G.M. Wrote the paper: E.G.M. Patient assessment: M.B., J.G.M., P.C., C.C., M.C.P.S. and P.A. Acquisition of data: G.A., J.G.M., P.C., C.C., M.C.P.S., P.A., G.E., M.B., J.A.G.A. and E.G.M. All authors reviewed the manuscript.

\section{Additional Information}

Supplementary information accompanies this paper at http://www.nature.com/srep

Competing financial interests: The authors declare no competing financial interests.

How to cite this article: Amo, G. et al. A Nonsynonymous FCER1B SNP is Associated with Risk of Developing Allergic Rhinitis and with IgE Levels. Sci. Rep. 6, 19724; doi: 10.1038/srep19724 (2016).

(c) (i) This work is licensed under a Creative Commons Attribution 4.0 International License. The images or other third party material in this article are included in the article's Creative Commons license, unless indicated otherwise in the credit line; if the material is not included under the Creative Commons license, users will need to obtain permission from the license holder to reproduce the material. To view a copy of this license, visit http://creativecommons.org/licenses/by/4.0/ 